\title{
Quality of life evaluation in patients affected by osteoarthritis secondary to congenital hip dysplasia after total hip replacement
}

\author{
Alessandra Tellini - Vincenza Ciccone - Davide Blonna • \\ Roberto Rossi · Antongiulio Marmotti · Filippo Castoldi
}

Received: 1 October 2007/ Accepted: 28 June 2008/Published online: 16 August 2008

(C) Springer-Verlag 2008

\begin{abstract}
Background The aim of the study was to evaluate the quality of life (QoL) in patients affected by osteoarthritis (OA) secondary to congenital hip dysplasia (CHD) and treated by hip arthroplasty.

Methods We prospectively treated 40 patients admitted to our hospital between 2001 and 2006. Each patient was asked to answer to two questionnaires: WOMAC and MOS SF-36. Patients were evaluated four months before surgery and once they had achieved postoperative rehabilitation. Pre- and postoperative results were analyzed and compared with the international literature on patients affected by OA and also with a healthy population.

Results Pre- and post-operative results: WOMAC: pain 14.06-0.84; stiffness 4.26-0.52; function 42.68-5.39. SF36 : physical function 18.55-84.52; role physical 28.3387.10; body pain 23.26-83.39; general health 55.19-81.74; vitality 32.74-72.10; social function 43.55-84.66; role emotional 68.82-93.55; mental health 48.77-79.35. All results were statistically significant.

Conclusions The study reports an important QoL improvement in patients affected by arthritis secondary to CHD that underwent hip surgery, and underlines differences with respect to primary OA. QoL evaluation cannot
\end{abstract}

\footnotetext{
A. Tellini $(\bowtie) \cdot$ D. Blonna $\cdot$ R. Rossi · A. Marmotti ·

F. Castoldi

Orthopaedic and Traumatology Department,

Mauriziano "Umberto I" Hospital,

University of Turin Medical School,

Largo Turati 62, 10128 Torino, Italy

e-mail: aletel@yahoo.com

V. Ciccone

Radiology Department, Molinette Hospital,

University of Turin Medical School, Torino, Italy
}

replace either clinical and instrumental evaluation or the physician's experience, but it can give weight to the patient's expectations, and may be considered an efficient test for medical and surgical treatments.

Keywords Hip · Arthritis - Total hip replacement . Congenital hip dysplasia

\section{Introduction}

Quality of life (QoL) has been defined by the World Health Organization (WHO) as a "multidimensional" model which includes physical, material, social and emotional wellbeing, as well as individual development and daily activity [1]. The complexity of this concept makes it challenging to create validated instrumentation for the evaluation of QoL after treatment.

Clinical and functional characteristics of patients treated with total hip replacement (THR) for congenital hip dysplasia (CHD) differ from those treated for primary hip osteoarthritis (OA), in part due to the lower mean age of those affected by CHD. The primary aim of this study was to assess quality of life after total hip replacement in patients with CHD, using one general and one specific validated QoL indicator. We compare our results to the published literature on QoL in OA patients, and assess the relative validity of these instruments in the CHD population.

\section{Materials and methods}

Study approval was obtained from the ethical committee of our institution, in full compliance with the Declaration of 
Helsinki. All patients gave their consent to participate in this study prior to case review.

Between June 2001 and January 2006, we identified patients who underwent total hip arthroplasties (THA) performed by the senior author. The inclusion criterion was diagnosis of OA secondary to CHD (Crowe's classification type I or II). The exclusion criterion was revision hip surgery.

Each patient was asked to answer two questionnaires by phone, the Short-Form 36 (SF-36) and the Western Ontario and MacMaster University Osteoarthritis Index (WOMAC). The SF-36 is a generic measure of QoL with 36 questions. It consists of an eight-scale profile of functional health and well-being, as well as psychometrically based physical and mental health summary measures. The SF-36 is often used as point of reference for other tests $[2,3]$. Final score is proportional to individual well-being $[4,5]$. The WOMAC is a validated instrument designed specifically for the assessment of lower extremity pain and function. Usually self-administered, the WOMAC assesses pain, disability and joint stiffness in knee and hip osteoarthritis using a battery of 24 questions. It is useful for the clinical evaluation of disease treatment, specifically for short-term investigations [6-8]. Final score is proportional to individual disability.

The questionnaires were adminstered pre-operatively, and at a minimum of four months after rehabilitation was completed. The questionnaires were scored per their respective operating manuals $[9,10]$. All results were compared with the published literature, and SF-36 results were also compared with those of healthy Italian populations aged 45-54 years, corresponding to the study cohort's mean age $[4,5,8,11,13-18]$.

The standard deviation (SD) and effect size (a measure of the strength of the difference between two groups) was calculated for each survey item pre- and post-operatively [11]. Each item was also analyzed for normality (Kolmogorov-Smirnov test). The Student $t$-test was used for paired comparisons when the data was normally distributed, and the Wilcoxon signed-ranks test for nonparametric data. Significance was set at 0.05 . Data analysis was carried out using SPSS (Chicago, IL, USA).

\section{Results}

We identified 40 THAs in 40 consecutive patients performed by a single surgeon. Four patients were unavailable for survey completion. Three patients were excluded due to revision surgery, and two patients were excluded as they had not yet completed their rehabilitation. The study group was thus composed of 31 patients. There were 28 females and 3 males, with a mean age at surgery of 51 years (range 33-70). The mean follow-up time was 36 months (range 460). There were 13 patients with a Type I Crowe classification, and 18 patients with a type II classification. All cases utilized a Conus-type stem and a Fitmore-type cup (Zimmer GmbH, Winterthur, Switzerland).

Results from the SF-36 are collated in Table 1. Effect sizes of of 0.2, 0.5 and 0.8 indicate small, medium and large differences, respectively. The effect size (ES) for physical functioning was $\mathrm{ES}=3.72$, ES for bodily pain $=2.45$, and $\mathrm{ES}$ for role emotional $=0.61$.

The percentage relative increase ranged from 36 to $356 \%$. All values were statistically significant for $P<0.05$.

Results from the WOMAC are collated in Table 2. As a reminder, the final score is proportional to individual disability, i.e., a patient with less pain/disability should have a lower score. Once again, the ES and percentage relative increase demonstrated statistically significant improvements between the patients' pre- and post-operative values.

\section{Discussion}

In this study, $100 \%$ of all questionnaire items were obtained, which should be compared with the literature,

Table 1 SF-36 results

\begin{tabular}{|c|c|c|c|c|c|}
\hline Scale & $\begin{array}{l}\text { Pre-operative } \\
\text { mean value }(\mathrm{SD})\end{array}$ & $\begin{array}{l}\text { Post-operative } \\
\text { mean value }(\mathrm{SD})\end{array}$ & $P$ value & Effect size & $\begin{array}{l}\% \text { Relative } \\
\text { increase }\end{array}$ \\
\hline Physical functioning & $18.55(17.71)$ & $84.52(12.67)$ & 0.000 & 3.72 & 355.47 \\
\hline Role physical & $28.33(41.20)$ & $87.10(24.89)$ & 0.000 & 1.43 & 207.45 \\
\hline Bodily pain & $23.26(24.59)$ & 83.39 (19.67) & 0.000 & 2.45 & 258.51 \\
\hline General health & $55.19(23.26)$ & $81.74(15.39)$ & 0.000 & 1.14 & 48.11 \\
\hline Vitality & $32.74(28.78)$ & $72.10(17.78)$ & 0.000 & 1.37 & 120.22 \\
\hline Social functioning & $43.55(29.73)$ & $84.66(18.17)$ & 0.000 & 1.38 & 94.40 \\
\hline Role emotional & $68.82(40.31)$ & $93.55(20.04)$ & 0.011 & 0.61 & 35.93 \\
\hline Mental health & $48.77(32.26)$ & 79.35 (14.68) & 0.000 & 0.95 & 62.70 \\
\hline
\end{tabular}


Table 2 WOMAC results

\begin{tabular}{lclllc}
\hline Scale & $\begin{array}{l}\text { Pre-operative } \\
\text { mean value (SD) }\end{array}$ & $\begin{array}{l}\text { Post-operative } \\
\text { mean value (SD) }\end{array}$ & $P$ value & Effect size & $\begin{array}{l}\text { \% Relative } \\
\text { increase }\end{array}$ \\
\hline Pain & $14.06(5.05)$ & $0.84(1.83)$ & 0.000 & 2.62 & $1,573.80$ \\
Stiffness & $4.26(2.62)$ & $0.52(0.99)$ & 0.000 & 1.43 & 719.23 \\
Function & $42.68(12.83)$ & $5.39(5.70)$ & 0.000 & 2.91 & 691.84 \\
Global & $61(17.35)$ & $6.74(7.41)$ & 0.000 & 3.13 & 805.04 \\
\hline
\end{tabular}

where up to $5.3 \%$ of all answers are missing, contradictory or multiple [12].

Patients in the THA literature generally have primary osteoarthritis [11, 13, 14]. Osteoarthritis secondary to CHD usually represents only $2-3 \%$ of all diagnoses $[11,14]$. With respect to the SF-36 survey, our results were equivalent or better than studies where primary OA was the principal diagnosis (with higher patient mean ages) (Fig. 1).

Published role-physical preoperative values range from 19.5 to 27.05 , and post-operative values from 52.41 to 66.6, while these values ranged from 18.55 to 84.52 in our patient cohort $[11,13,14]$. We noticed the same tendency for the bodily pain scale, with preoperative values ranging from 27.1 to 32.90 and post-operative values from 58.79 to 72.8 in the literature, versus a range of 23.26-83.39 in our study $[11,13,14]$. General health and vitality pre-operative values in our study were mainly lower than in the literature, and post-operative values were higher $[11,13,14]$. Roleemotional values were higher both pre- and post-operatively in our study [11, 13].

A lower mean age, with a resultant lower comorbidity disease burden, may explain why our patient cohort achieved higher final post-operative clinical SF-36 results than primary OA patients from the literature [19]. Patients in our cohort had lower pre-operative mental health scores than the published literature: younger patients may be less able to cope with functional limitations than their older peers. Post-operative scores were similar (79.4 vs. 79.4). This reasoning may equally apply to social functioning as well.

Interestingly, our patient cohort displayed better postoperative results on the SF-36 than healthy controls aged 45-54 years, except for the role-physical scale (Fig. 2). This could have been due to a recall bias: recently rehabilitated patients may have tended to overvalue their current physical condition when making a pre-operative comparison (when the clinical and psychological effects of their condition were presumably at their worst).

Comparison of our patients with the literature using the WOMAC was complicated by the diverse methods used to report results (raw score, percentage, visual analog scale) [8, 15-18]. We generally observed a greater score decrease (meaning improvement in QoL) among our cohort (Fig. 3). This was probably due to the relatively lower mean patient

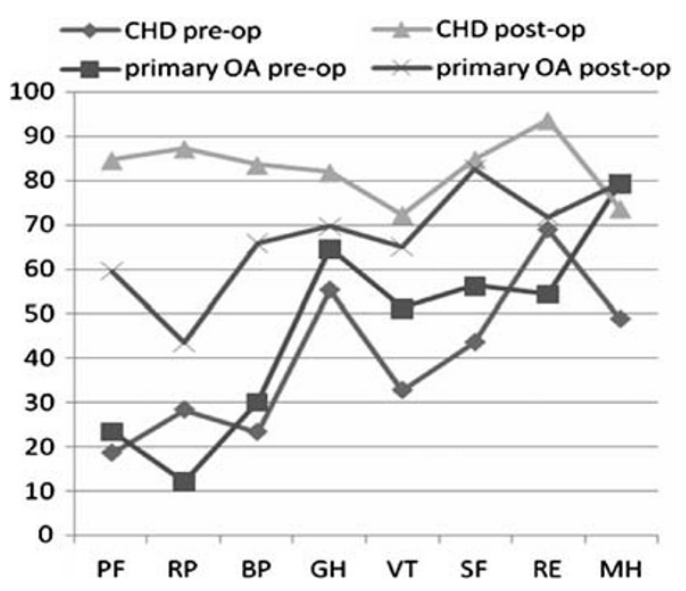

Fig. 1 SF-36 pre and post-operative results in CHD and primary hip OA $[11,13,14]$

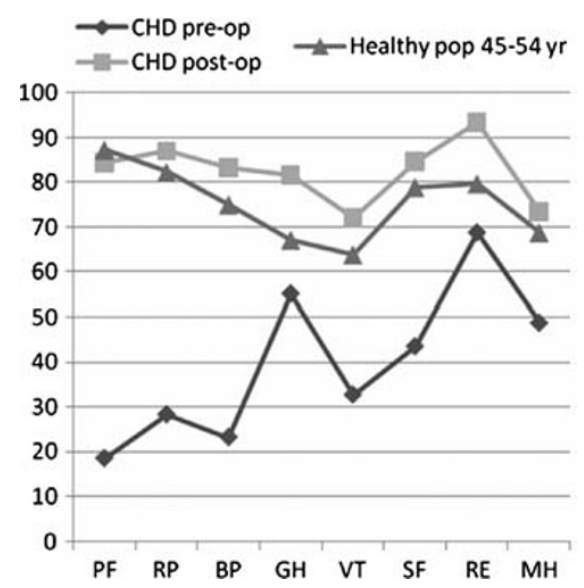

Fig. 2 SF-36 pre- and post-operative results in CHD and healthy populations in the $45-54$-year-old age group $[4,5]$

age (51 vs. 65-68 years), and to clinical differences between CHD and primary OA [11, 13].

Considering that CHD essentially affects young women, social functioning and mental health evaluation is critical: it has been observed that females aged $<65$ years who are affected by chronic disease suffer more frequently from psychological disorders than men [14].

Our results indicate that both the SF-36 and WOMAC are valid and complementary evaluation instruments. The WOMAC assesses physical outcomes, while the SF-36 is 


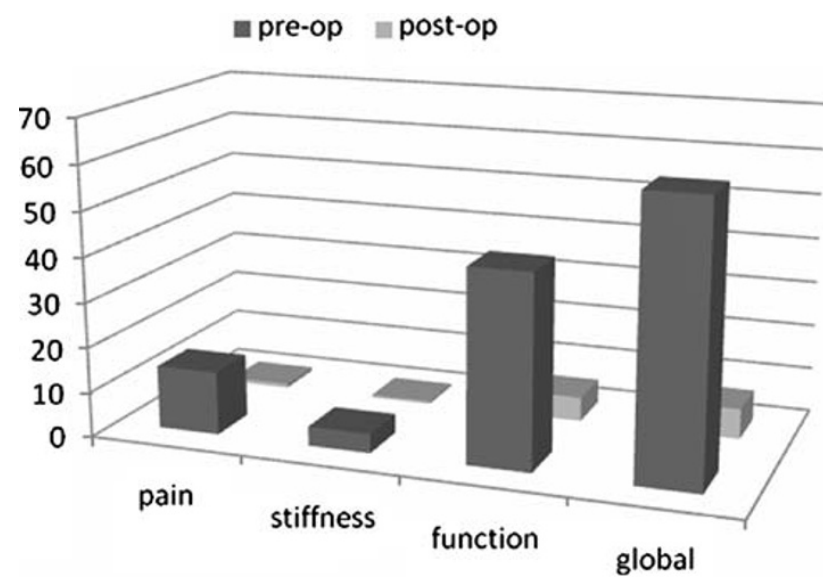

Fig. 3 WOMAC pre- and post-operative results

mostly dedicated to the social and psychological arena [21]. Utilization of these QoL indicators alongside more traditional evaluation instruments, such as the Harris hip score, continues to increase in the literature $[14,20]$.

Orthopedic surgeons may wish to address clinical decision-making from not only physical and radiologic findings but also the context of QoL: the timing of an operation can, for example, be delayed until any attendant psychological or social concerns are addressed. That being said, quality of life evaluations should neither replace clinical and radiographic examination nor be used independently as the basis for a surgical indication [19]. Quality of life evaluation may help with the qualitative determination of the patient's motivations and expectations for joint replacement. QoL questionnaires can also be used for patient follow-up and satisfaction, either alone or in concert with other surveys [7, 8, 22-24].

Conflict of interest statement The authors had no competing interests, financial or otherwise, in the development of the study.

\section{References}

1. The WHOQOL Group (1998) The World Health Organization Quality of Life Assessment (WHOQOL): development and general psychometric properties. Soc Sci Med 46(12):1569-1585

2. De Girolamo G, Rucci P, Scocco P, Becchi A, Coppa F, D'Addario A, Darù E, De Leo D, Galassi L, Mangelli L, Marson C, Neri G, Soldani L (2000) Quality of life evaluation: validity of short-WHOQOL. Epidemiol Psichiatr Soc 9(1):45-55 (Italian)

3. Ware JE, Keller SD, Gandek B, Brazier JE, IQOLA Sullivan M, Group Project (1995) Evaluating translation of health status questionnaires: methods from the IQOLA Project. Int J Technol Assess Health Care 11:525-551

4. Apolone G, Cifani S, Mosconi P (1997) SF-36 health questionnaire. Translation and validity of Italian version: IQOLA project results. Medic 2:86-94

5. Apolone G, Mosconi P, Ware JE (1997) SF-36 health questionnaire. Manual for use and guide to interpreting the results. Guerini e Associati, Milan, Italy
6. Bellamy N (2005) The WOMAC knee and hip osteoarthritis indices: development, validation, globalization and influence on the development of the AUSCAN hand osteoarthritis indices. Clin Exp Rheumatol 23(Suppl 39):148-153

7. Bellamy N, Buchanan W, Goldsmith C, Campbell J, Stitt L (1988) Validation study of WOMAC: a health status instrument for measuring clinically important patient relevant outcomes to anti-rheumatic drug therapy in patient with osteoarthritis of the hip or knee. J Rheumatol 15:1833-1840

8. Salaffi F, Carotti M, Grassi W (2005) Health-related quality of life in patient with hip or knee osteoarthritis: comparison of generic and disease-specific instruments. Clin Rheumatol 24:29-37

9. Ware JE, Snow KK, Kosinski M, Gandek B (1993) SF-36 health survey: manual and interpretation guide. The Health Institute, New England Medical Centre, Boston, MA

10. Bellamy N (2008) WOMAC 3.1 index webpage. http://www. auscan.org/womac/index.htm. Last accessed 27 July 2008

11. Ostendorf M, Van Stel HF, Buskens E, Schrijvers JP, Marting LN, Verbout AJ, Dhert WJA (2004) Patient-reported outcome in total hip replacemet. A comparison of five instruments of health status. J Bone Joint Surg Br 86:801-808

12. McGrory J, Shinar AA, Freiberg AA, Harris WH (1997) Enhancement of the value of hip questionnaires by telephone follow-up evaluation. J Arthroplasty 12(3):340-343

13. Bachmeier CJM, March LM, Cross MJ, Lapsley HM, Tribe KL, Courtenay BG, Brooks PM (2001) A comparison of outcomes in osteoarthritis patients undergoing total hip and knee replacement surgery. Osteoarthritis Cartilage 9:137-146

14. Lieberman JR, Dorey F, Shekelle P, Schumacher L, Kilgus DJ, Thomas BJ, Finerman GA (1997) Outcome after total hip arthroplasty. Comparison of a traditional disease-specific and quality-oflife measurement of outcome. J Arthroplasty 6:639-645

15. Johanson NA, Liang MH, Daltroy L, Rudicel S, Richmond J (2004) American Academy of Orthopaedic Surgeons lower limb outcomes assessment instruments. Reliability, validity, and sensitivity to change. J Bone Joint Surg Am 86A:902-909

16. Kelly KD, Kramer G, Johnston DWC, Redfern L, SuarezAlmazor ME (2000) The impact of health status on waiting time for major joint arthroplasty. J Arthroplasty 15(7):877-883

17. Kelly KD, Voaklander DC, Johnston DWC, Newman SC, SuarezAlmazor ME (2001) Change in pain and function while waiting for major joint arthroplasty. J Arthroplasty 16(3):351-359

18. Padua R, Romanini E, Gillio A, Bondì R, Ceccarelli E, Campi S, Pecorelli F (2005) Health-related quality of life after hip raplacement. J Orthop Traumatol 6:10-14

19. McGuigan FX, Hozack WJ, Moriarty L, Eng K, Rothman RH (1995) Predicting quality-of-life outcomes following total joint arthroplasty. Limitation of the SF-36 health status questionnaire. J Arthroplasty 10(6):742-747

20. Chiu HC, Mau LW, Hsu YC, Chang JK (2001) Postoperative 6month and 1-year evaluation of health-related quality of life in total hip replacement patient. J Formos Med Assoc 100(7):461465

21. Wright JG (1997) A comparison of different indices of responsiveness. J Clin Epidemiol 50(3):239-246

22. Dawson J, Linsell L, Zondervan K, Rose P, Randall T, Carr A, Fitzpatrick R (2004) Epidemiology of hip and knee pain and its impact on overall health status in older adults. Rheumatology 43:497-504

23. Ethgen O, Bruyere O, Richy F, Dardennes C, Reginster JY (2004) Health-related quality of life in total hip and total knee arthroplasty. A qualitative and systematic review of the literature. J Bone Joint Surg Am 86-A(5):963-974

25. Villani C, Romanini E, Giordano MC, Persiani P, Casella F (2000) Uncemented total hip prosthesis: patient's middle term follow-up evaluation. GIOT 26:67-73 